\title{
Study of the Stress Distribution Due to the Effect of Transient Analysis on a Vertical Pressure Vessel and Validation using the Mesh Independence Study
}

\author{
Faro A. A. ${ }^{1}$, Salam K. K. ${ }^{2 *}$, Jeremiah O. A. ${ }^{3}$, Akinwole I. O. ${ }^{2}$, Animashaun B.F. ${ }^{4}$ \\ ${ }^{1}$ FEDDO Integrated Service, Lagos, NIGERIA \\ ${ }^{2}$ Department of Chemical Engineering, \\ Ladoke Akintola University of Technology (LAUTECH), Oyo state, NIGERIA
}

${ }^{3}$ FEDDO PTY LTD, Perth, AUSTRALIA

${ }^{4}$ Department of Metallurgical and Materials Engineering,

University of Lagos, NIGERIA

*Corresponding Author

DOI: https://doi.org/10.30880/jamea.2021.02.01.001

Received 04 February 2021; Accepted 10 June 2021; Available online 02 August 2021

\begin{abstract}
The importance of Pressure Vessel (PV) to industries is one of the reasons why the design and structural integrity should be fully understood and considered when deploring it in under different conditions. The design of such vessels need to be broadened with a detailed thermal stress due to its time-dependent different behaviours experienced under load. Therefore, this study aimed at investigation of transient analysis of PV when subjected to different operating condition. The PV used for this simulation was designed based on American Society of Mechanical Engineers (ASME) Boiler and Pressure Vessel Code (BPVC) 2019 and subjected to transient-stress analysis (transient thermal and structural) using ANSYS software. A complete evaluation of temperature, heat flux and resulting stress distribution across the vessel was estimated at four different locations within the designed PV and the obtained result was compared with analytically obtained results from appropriate standards. The accuracy of the result obtained from PV was validated using analysis of Mesh Independent Study (MIS), Grid Convergence Index (GCI) and fractional error obtained between the fine grid used. The results showed that there were different temperature and heat flux distribution at the considered locations, these varied distributions or change are according to various transients which are as a result of the load applied to the PV. The simulated maximum principal stress value was close to the analytically computed stress with a percentage error of $2.65 \%$ with respect to the analytically obtained result. The analysed maximum stress (W analysed) value $3400 \mathrm{MPa}$, obtained from MIS study was close to $3210 \mathrm{MPa}$ obtained for maximum stress using numerical approach $\left(\boldsymbol{W}_{N}\right)$. The GCI value obtained was 0.073 and fractional error of -0.003 which show that the result presented are grid independent solution.
\end{abstract}

Keywords: ANSYS, pressure vessel, thermal, stress and heat flux, mesh independence study

\section{Introduction}

Pressure vessels are important equipment with versatile applications in different manufacturing and process engineering industries. They can be used as reactors and storage devices in nuclear engineering, a mixing chamber for chemical industries, oil refinery; the equipment is expected to work under normal operating range with comprising its safety and reliability. However, for most deplored areas of application, PV operational requirement is not the same for temperature and applied pressure. This variation translated to transient in the behaviour of PV, and inability to capture it properly can lead to compromise of the structure that can result in physical injuries to people around the facility and 
property damage. Therefore, PV should be subjected to both normal design operational conditions and conditions beyond their design limit by considering transient cases that estimate stress, fatigue, and structural integrity with respect to thermal load included in its design challenging. The importance of the normal operating condition of PV have been reported where there exists variation in temperature, heat flux, and stresses across elements of a PV [1], where different behaviour was observed for testing reliability of different materials used in the fabrication of PV [1, 2] and in the determination of thermal tolerance of PV to some processes [3]. Apart from normal operating conditions, a transient condition due to sudden or gradual change in the thermal (heat) condition of PV is important due to PV deployment for different engineering applications [4].

The significance of transient condition inside a PV was reported in the research of Katsuyama, et al. [5] where the effect of operator action time of two different design specifications (10 minutes for Japan and 30 minutes for U.S.) of PV used in nuclear plants when thermal-hydraulic method during pressurised thermal shock was imposed on PV. The trend of Japan and US are similar for heat transfer coefficient at the wall of the PV, the fluid temperature at the downcomer and fluid temperature at the downcomer during transient while the pressure and water level behaviour in the pressurised after $50 \mathrm{sec}$ for the US standard are greater than that of Japan specification with respect of time. In order to eliminate high risk in the form of structural weakening associated with PV subjected to pressure thermal shock, Gálik, et al. [6] conducted simulation into the thermo-hydraulic and thermo-mechanical loading of VVER-440 Reactor Pressure Vessel (RPV) while simulation the effect of transient on coolant (fluid) flow during Loss of Coolant Accident (LOCA) in VVER440 RPV [7]. The temperature distribution propagated at the PV wall thickness while the temperature at the outer surface of the RPV cooled over time. Coolant mixing generated a high non-uniform temperature distribution and created a strip cooling effect. The cooled strip in the RPV oscillated (not stable), and this oscillation could lead to fracture at the wall of the RPV. For the two investigations [3 \& 4], the possible crack initiation of the RPV was determined for the transient loads imposed.

The stress distribution due to transient load on the RPV was one of the areas that researchers investigated to maintain the safety consideration of this equipment. The stress distribution of a two-layered composite hollow cylindrical pressure vessel subjected to internal fluid pressure and thermal load under a transient state was reported [4]. The stress distribution values on the PV when the only thermal load was imposed on the PV was less than when both thermal and internal fluid pressure is imposed on the PV. Also, materials properties affected the change in stress experienced in the radial and loop stress distribution on the layers of the PV. Also, stress distribution was studied using the thermo-hydraulic computation method and Fracture Mechanics for the effect of cold-water injection mixing and temperature differential with hot water inside a PV. The mixing behaviour from the Computation Fluid Dynamics (CFD) shows that unilateral cooling produced a more stable cooling plume when compared with that of symmetry cooling and larger thermal shock was observed for two-phase flow when compared with a single-phase flow [8]. The transient thermal analysis of both temperature and heat flux distributions of a typical APR1400 PV under thermal loading was evaluated in the simulation of Maklago, et al. [9]. Stress analyses are performed on top flange, vessel cross-section, cold and hot leg nozzle location on the PV. The deductions are transients thermal undertaken was at $343{ }^{\circ} \mathrm{C}$ in the internal surface, and convection process was undergone at the outer surface, the cold leg of the PV experienced the maximum deformation and minimum heat flux when transient was imposed on the PV.

The behaviour of PV deplored to chemical industries, and related areas are important in order to determine the operational limit under which the PV can perform within the safety limit. In order to determine the design consideration for the pressure that will extend the life of PV used in the chemical industry against fatigue, Bhoknal et al., [10] conducted a simulation on transient dynamics stress of PV for combined effect of pressure and vibration at different chamber outer temperature. The results showed that after complete cycle at $37.79{ }^{\circ} \mathrm{C}$ was the best temperature under which the chamber can escape fatigue, and also the total stress and deformation are $39.29 \mathrm{MPa}$ and $0.1079 \mathrm{~mm}$. Modification of operating condition/unit operation by removing preheating stage during coking operation on the thermal stress analysis and thermal fatigue damage of a coke drum was investigated in 2018 [11]. The simultaneous cycle of high temperature and sudden cooling imposed on the coke drum affected the operational life more than other facilities in the oil refinery. In shortening the cycle time between the heavy residual feed oil and production of lighter oil and reducing fatigue life of a coke drum, transient thermal stress and thermal fatigue damage evaluation for skirt attached coke drum were conducted. The modelling tested the removal of preheat or cutting stage of cracking operation with respect of stress and reduction in time of production. It was observed that the stress as a removal of preheat was lower than that of cutting stage from the operation sequence. For removal of preheat, $19 \%$ reduction in fatigue of coke drum was experienced while it was increased to $39 \%$ when cutting stage was removed. With the removal of preheat, the temperature profile was relatively stable over time while that of cutting stage change with change in time.

It was deduced from reviewed literature stress analysis on PV should be conducted, but researchers did not consider loaded thermal values on the structure of PV, and the influence of mesh sizes was not tested on their simulation. PV is an important piece of equipment with its application cutting across manufacturing and process engineering industries. Integrity and safety are important to any design because, if compromised, they could lead to severe damage. PV responses to loads under transients are different for the various deployed area of application, which means that overlooking operating transients can trigger complications in estimating the stress and failure across the entire PV. Therefore, this 
CFD simulation will report findings on thermal-stress analysis imposed on vertical PV, which will be validated using ASME Boiler and Pressure Vessel Code (BPVC) [12].

\section{Methodology}

\subsection{Design and Finite Element Analysis (FEA) of PV}

The PV design used for this analysis can be found in Faro et al. [13] where the stress analysis of vertical PV was investigated and current work is an extension to this work where thermal loads on this PV are analysed. Table 1 and 2 are the PV design specification and the input data into the simulator. The PV was subjected to transient analysis and stress distribution on the PV after undergoing transient analysis was simulated using static structural. The boundary conditions imposed on the designed PV for both the thermal (a) and static structural (b) are shown in Fig. 1.

Table 1 - Input factors for PV design

\begin{tabular}{clc}
\hline S/No & Parameters & Values \\
\hline 1 & Head Internal Diameter, mm & 2134 \\
2 & Head Thickness, mm & 27 \\
3 & Head Outer Diameter, mm & 2188 \\
4 & Shell Internal Diameter, mm & 2134 \\
5 & Shell Outer Diameter, mm & 2182 \\
6 & Shell Thickness, mm & 24 \\
7 & Length of Shell, mm & 6096 \\
8 & Length of Head & 1076 \\
9 & Internal Pressure (Pi), Pa & 10 \\
10 & Young Modulus, GPa & 200 \\
11 & Poisson Ratio & 0.30 \\
12 & Design Pressure (Pd), Pa & 157500 \\
13 & Inner Temperature, deg. C & 1300 \\
14 & Outer Temperature, deg. C & 200 \\
\hline
\end{tabular}

Table 2 - The input data used for the numerical analysis

\begin{tabular}{clc}
\hline S/No & Data & Values \\
\hline 1 & Inner Temperature, deg. C & 1300 \\
2 & Height of the vessel, m & 8.245 \\
3. & Design pressure, MPa & 15.75 \\
4. & Internal pressure, Pa & 10 \\
5. & Young modulus, GPa & 200 \\
6. & Length of Ellipsoidal head, m & 1.076 \\
7. & Thermal conductivity ( k), w/mk & 50.9 \\
8. & Inner radius (r1), m & 1.067 \\
9. & Outer radius, (r2), m & 1.091 \\
10. & Thermal coefficient of expansion & $12 \mathrm{E}-6$ \\
\hline
\end{tabular}

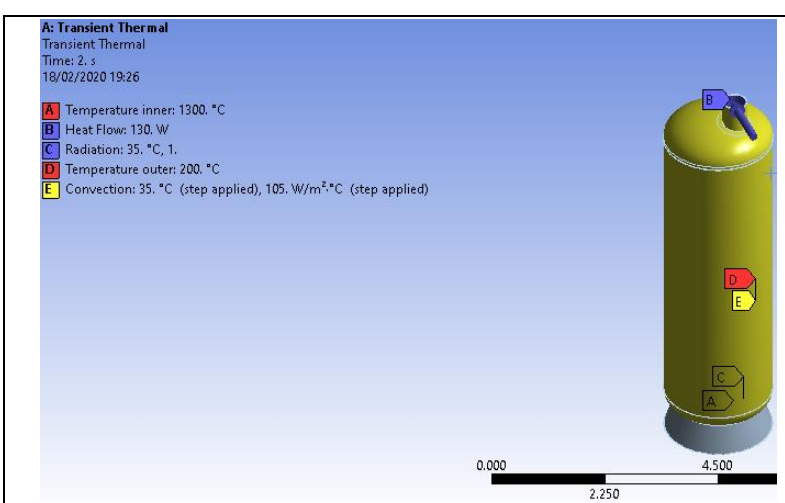

(a)

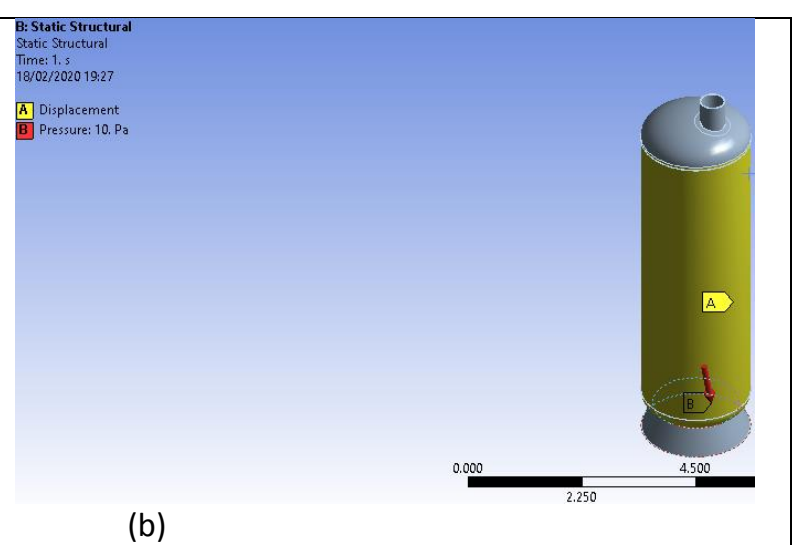

(b)

Fig. 1 - Boundary imposed on the designed PV for (a) thermal; (b) static structural, respectively 
The steps adopted using Finite Element Analysis (FEA) in this research are Pre-processing (mesh generation, boundary condition and model display), solution and post-processing, respectively. In the present study, geometric modelling of the vertical PV was achieved using ANSYS workbench, and its simulation is performed using the same. The element's material is acted with the pressure inside in one case and the temperature in the other.

The second law of thermodynamics was obeyed because the setup requires two reservoirs to transmit the heat. One of the reservoirs was an inner portion of the vessel where the temperature was high, while the other was for an observed temperature distribution from inner to the outer portion; the material choice is structural steel, although different material can be chosen accordingly by changing the thermal conductivity of the material. The PV element is modelled, and it is meshed using ANSYS software.

After this step a structural and thermal steady-state simulation is performed. By using ANSYS numerical simulation tool, the whole analysis of the entire assembly is performed. For transient analysis simulation, this study computed the boundary conditions values for thermal conductivity, heat flux, heat rate and heat flow presented in equations (1) - (6). For structural analysis, a pressure value of $10 \mathrm{~Pa}$ is applied inside the analysis. At the end of the design and modelling, transient temperature and heat flux in the PV walls are analysed due to the thermal loads. Furthermore, the design was subjected to structural analysis where variables such as the maximum displacement, principal stress and shear stress distribution under the operating pressure were analysed.

\subsection{Analytical Method}

\subsubsection{Computation of Transient Boundary Condition}

Before transient simulation can be embarked upon, heat flow, heat flux and heat rate values were estimated and supplied as input to the ANSYS simulation. A 1-D steady-state conduction with no thermal energy generation was used to model the heat flow scenario, and the full explanation and derivation can be found in the open course ware released by the Massachusetts Institute of Technology (MIT) [14] while equations (1) - (6) were used for the computation of heat flow, heat flux and heat rate respectively.

$$
\begin{gathered}
\text { Heat Flow, } \mathrm{q}=\frac{2 \pi \mathrm{k}}{\mathrm{rIn}\left(\frac{\mathrm{r}_{2}}{\mathrm{r}_{1}}\right)}\left(\mathrm{T}_{1}-\mathrm{T}_{2}\right) \\
\mathrm{q}=\frac{50.9(1100)(2 \pi)(8.245)}{0.024(0.02225)}=130 \times 10^{6} \mathrm{w} \\
\mathrm{q}_{\mathrm{f}}=\frac{50.9(1100)}{0.024(0.02225)}=105 \times 10^{6} \mathrm{w} / \mathrm{m}^{2} \mathrm{k} \\
\text { Heat Flux, } \mathrm{q}_{\mathrm{f}}=\frac{\mathrm{k}}{\mathrm{rIn}\left(\frac{\mathrm{r}_{2}}{\mathrm{r}_{1}}\right)}\left(\mathrm{T}_{1}-\mathrm{T}_{2}\right) \\
\mathrm{q}_{\mathrm{r}}=\frac{50.9(1100)(2 \pi)}{0.024(0.02225)}=158 \times \mathrm{x}^{6} \mathrm{w} / \mathrm{m}^{\mathrm{HIn}\left(\frac{\mathrm{r}_{2}}{\mathrm{r}_{1}}\right)}\left(\mathrm{T}_{1}-\mathrm{T}_{2}\right)
\end{gathered}
$$

\subsection{Validation of the Simulation}

This simulation was validated by comparing the value of maximum stress computed from the derivation of stress value from equations 7-11 with that of simulated values (Maximum principal stress). The pressure vessel is designed to meets all the requirements of ASME Boiler and Pressure Vessel Code (BPVC). Expansion due to thermal stress in a link and structural forces can be determined using equations (7) and (8):

$$
\begin{gathered}
\delta=\alpha \Delta \mathrm{TL} \\
\delta=\frac{\mathrm{PL}}{\mathrm{EA}}
\end{gathered}
$$

Making subject of the formula, equation 9 was derived and used for the computation of principal stress. The value obtained from this analytical method will be compared with the simulated maximum principal stress after simulation 
using ANSYS. From the Hooke's law, ultimate stress can be presented using equation 9. Equation 11 is the result of the validation by calculation of the ultimate stress of the PV.

$$
\begin{gathered}
\delta=\frac{\mathrm{F}}{\mathrm{A}}=\alpha \Delta \mathrm{TE} \\
\delta=\left(12 \times 10^{6}\right)(1100)\left(200 \times 10^{3} \mathrm{MPa}\right) \\
\delta=2.64 \times 10^{9} \mathrm{~Pa}
\end{gathered}
$$

Where $\delta$ is ultimate stress, $\alpha$ is coefficient of expansion, $\Delta T$ is change in temperature, $L$ is length, $P$ is axial load, $E$ is young modulus, and $A$ is area. The closer the analytically calculated and simulated result from ANSYS the better the simulation result.

\subsection{Mesh Refinement Study (MRS)}

MRS was conducted on the designed PV through analysis of Mesh Independent Study (MIS) and Calculation Verification, respectively. Mesh Independent study was determined around Maximum stresses, calculated using a linear static model and the method adopted are Calculation Verification (CV) [15], and the grid selected was validated using GCI [16]. For CV method, mesh element sizes were progressively increased while corresponding Maximum stresses were recorded for each simulation. The mesh element sizes of a tetrahedral mesh considered are 90, 95, 100, 120, 150 and $180 \mathrm{~mm}$, respectively.

The order of accuracy for the exact mesh size was determined using equation 12 for three (3) best consecutive MS at different mesh element sizes.

$$
W_{i}=W_{h i}+A h_{i}^{p}+H \text { as } h \rightarrow 0
$$

Where $\mathrm{A}=$ constant, $\mathrm{H}=$ Higher-order terms, which tend to zero faster than the lowest order error term (the second term on the right) as $\mathrm{h}$ tends to zero, $h_{i}=$ grid size (finest, intermediate and coarse sizes), $W_{i}=\mathrm{MS}, \mathrm{p}=$ order of accuracy and $W_{h i}=$ numerical MS at any grid size, hi.

The grid size was assumed to be small enough that the $\mathrm{H}$ is negligible compared to the lowest order error term. When this is so, the numerical solution is said to be in the Asymptotic Convergence regime. The derived equations when equation 12 was used for the three-element sizes (90 mm denotes as $1,95 \mathrm{~mm}$ denotes as 2, and $100 \mathrm{~mm}$ denotes as 3 ) were used where subscript 1,2,3 referred respectively to the finest, intermediate, and coarsest numerical solutions for the System Response Quantities (SRQ) of interest. The steps adopted for the computation of W exact are presented in equation $(13)-(24)$.

Re-arranging,

$$
\begin{aligned}
& \mathrm{W}_{1}=3410.2+\mathrm{A}\left(90^{\mathrm{P}}\right) \\
& \mathrm{W}_{2}=3420.7+\mathrm{A}\left(95^{\mathrm{P}}\right)
\end{aligned}
$$

$$
\begin{gathered}
\mathrm{W}_{3}=3456.3+\mathrm{A}\left(100^{\mathrm{P}}\right) \\
\mathrm{W}_{1}=3410.2+90 \mathrm{~A}^{\mathrm{p}} \\
\mathrm{W}_{2}=3420.7+95 \mathrm{~A}^{\mathrm{p}} \\
\mathrm{W}_{3}=3450.3+100 \mathrm{~A}^{\mathrm{p}}
\end{gathered}
$$

Eliminating A and rearrangement leads to

$$
\frac{\mathrm{W}_{2}-\mathrm{W}_{1}}{\mathrm{~W}_{3}-\mathrm{W}_{2}}=\frac{\mathrm{h}_{1}^{\mathrm{p}}-\mathrm{h}_{2}^{\mathrm{p}}}{\mathrm{h}_{2}^{\mathrm{p}}-\mathrm{h}_{3}^{\mathrm{p}}}
$$

Subscript 1, 2, 3 refer respectively to the finest, intermediate, and coarsest numerical solutions for the SRQ (System Response Quantities) of interest. 


$$
\begin{gathered}
p=\frac{\ln \frac{W_{3}-W_{2}}{W_{2}-W_{1}}}{\ln \left(h_{2} / h_{1}\right)} \\
W_{N}-W_{1}=\frac{\epsilon}{\left(h_{2} / h_{1}\right)^{p}-1} W_{1} \\
\epsilon=\left(W_{1}-W_{2}\right) / W_{1}
\end{gathered}
$$

Where $W_{N}$ is Richardson extrapolation based on three grids, and $\epsilon$ is the estimated fractional error in the fine grid solution. This value of $W_{N}$ is a Richardson extrapolation based on three grids. Equations (22) and (24) were used for computation of fractional error and exact maximum stress $\left(\mathrm{W}_{\mathrm{N}}\right)$

$$
\begin{gathered}
\epsilon=\frac{(3410.2-3420.7)}{3410.2}=\frac{-10.5}{3410.2}, \epsilon=-0.0031 \\
W_{N}-3410.2=\frac{-0.0031}{(95 / 90)^{1.05}-1}(3410.2) \\
W_{N}=\left[\frac{-0.0031}{(1.05)^{1.05}}(3410.2)\right]+3410.2 \\
W_{\mathrm{N}}=3210.74
\end{gathered}
$$

However, to standardise reporting numerical error estimates, GCI was defined as a grid-based on the right side of equation (8), and it has been fairly widely adopted in the CFD Community. Dividing equation (8) by $w_{1}$ and multiplying by a factor of safety $\left(F_{s}\right)$ of 1.25 for convergence studies with a minimum of 3 grids to demonstrate the observed order of convergence [16].

$$
\begin{gathered}
\mathrm{GCI}=\mathrm{F}_{\mathrm{S}} \frac{|\epsilon|}{\left(\mathrm{h}_{2} / \mathrm{h}_{1}\right)^{\mathrm{p}}-1} \\
\mathrm{GCI}=(125) \frac{|-0.0031|}{0.053} \\
\mathrm{GCI}=0.073
\end{gathered}
$$

Equations (13) - (25) were used with the sole aim to establish a validation sequence for the result gotten from the PV using a simulation model. Validation assessments are model accuracy assessments by comparing results obtained from either experiment with prediction or analysed obtained from simulation and determination of accuracy based on set rules. In addition, it is commonly necessary to assess the accuracy of a model's predictions for conditions where experimental data are not available (i.e., where extrapolation of the model is required). Experimental measurement for the pressure vessel is expensive; therefore, the conditions for validation with respect to the ASME V\&V [15] and Roache [16] will be used for the validation of the designed PV.

\section{Results and Discussion}

\subsection{Validation through MRS}

The stress metric is used to assess the validity of the model. The value of an unknown model parameter is first estimated from a variation of element size with the respective response (in this case, MS) was presented in Fig. 3. The obtained MS measurement was used for computation of GCI, and errors which are all used in validation assessment was tabulated in Table 3.

Maximum Stress from the Six (6) mesh sizes was plotted. The blue line is a best fit line through the three smallest element sizes. This line, or the calculation in Section 7.2 of ASME V\&V [15], can be used to extrapolate the maximum stress to a zero-size element. We varied different element sizes to obtain validation data to obtain various equivalent stresses and predicted the maximum stress with respect to element sizes tending zero approaches, as indicated in Figure 3. The resulting MS deflection is recorded as $3400 \mathrm{MPa}$. This MIS procedure and result obtained for this accuracy of the 
mesh used for this study was similar to the trend of MIS result obtained by the simulation study conducted by Kulkarni et al.[17] where three mesh sizes coarse, medium and fine where used to determine the accuracy of the CFD solution used for the modelling of a straight blade horizontal axis tidal turbine.

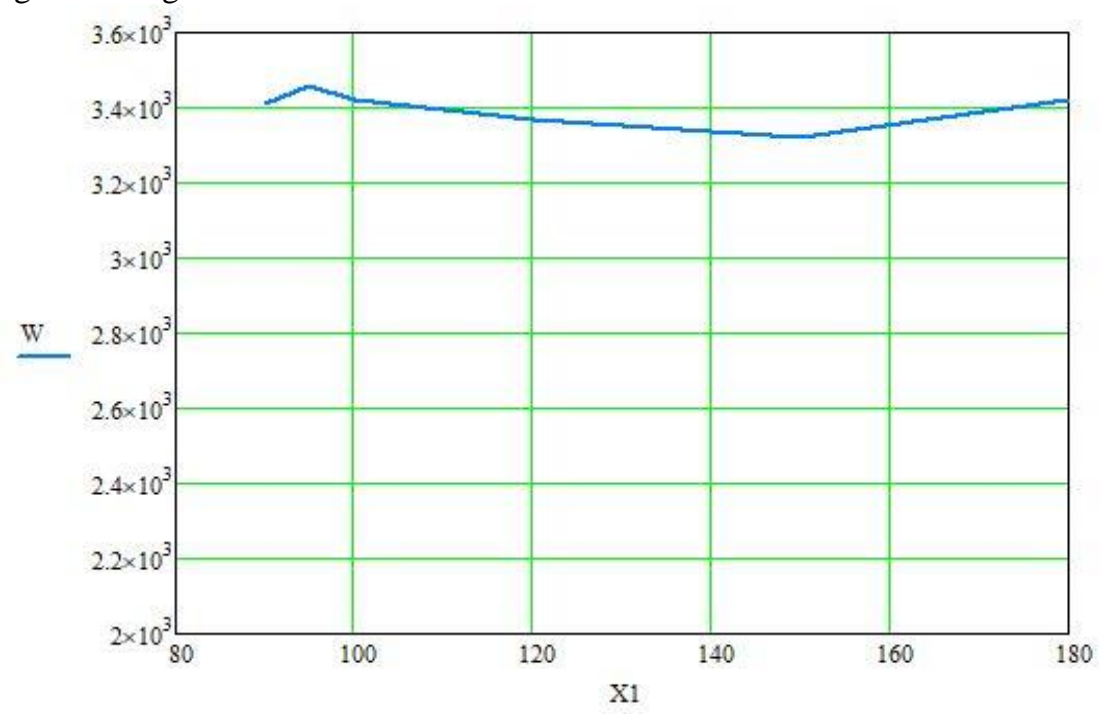

Fig. 2 - MS recorded for different element sizes

The number of finite elements needed to demonstrate that the numerical solution error is negligible, as determined by the calculation verification procedure above. The equivalent tip stress predicted by the model from equation (9) is 3210.74 MPa. GCI provided information on the grid, and the error bound that indicating the convergence of the solution obtained. The estimated fractional error obtained was -0.0031 (from equation 10), the value was a good approximation with good accuracy $(\epsilon<1)$ for a fine grid between $W_{1}$ and $W_{2}$. The calculated GCI value was 0.073 (11), a value less than 0.08 , which implies that the grid selected is solution independent [16].

Table 3 - Validation results from MIS analysis

\begin{tabular}{cc}
\hline Parameters & Values \\
\hline$W_{N}(M P a)$ & 3210.74 \\
$W_{\text {analysed }}(\mathrm{MPa})$ & 3400 \\
$\epsilon(\%)$ & -0.0031 \\
$G C I(-)$ & 0.073 \\
\hline
\end{tabular}

\subsection{Transient Analysis}

Temperature and heat flux distribution when PV was under load (Inner and outer temperature, convection, heat flow, and radiation) are considered under transient analysis, as shown in Figure 3. The influence of load on the PV shows that all the locations within the PV experienced the corresponding transient by the walls of the PV; Transient has a significant contribution to the structural integrity of PV. The result shows that the influence of the transient was more at the opposite wall/side of the PV. This means that there was a transfer in temperature during fluid contact with the wall of a vertical PV. On test of the integrity of PV by imposing constraint at the top of the PV show that less effect was observed at the top of the PV but imposing loads at the top cause a high transient behaviour at the bottom of the PV. The transient behaviour at the bottom of the PV was low and the influence of transient was observed towards the middle of the PV where the average temperature recorded was $495^{\circ} \mathrm{C}$.

The temperature distribution at different locations top of the PV, bottom, side and the whole of the PV was presented in Figure 4. It was observed that there was an increase in temperature with time for all the four locations considered on the PV. However, the temperature distribution on the side of the PV has the highest value with respect to time.

In Fig. 5, the heat flux distribution behaviour was similar to the behaviour observed for temperature distribution on PV. The bottom and top of the PV have the lowest distribution with heat flux values around 9.69x10 5 , while the walls of the PV show an increase in flux distribution which has values greater than those of the bottom and top of the PV. Transient has a significant contribution to the structural integrity of PV. The result shows an increase in heat flux at the PV walls compared with other parts of the PV at the opposite wall/side of the PV. The integrity of PV by imposing constraint at the top of the PV shows that less effect was observed at the top of the PV, but imposing loads at the top cause a high increase in heat flux at the bottom of the PV. The range of heat flux was from 2.22 to $8.14 \times 10^{6} \mathrm{~W} / \mathrm{m}^{2}$. Maximum heat 
flux was recorded at the base of the PV when load was imposed on top of the PV. The transient behaviour at the bottom of the PV was low, and the influence of transient was observed towards the middle of the PV where the average temperature recorded was $495^{\circ} \mathrm{C}$.

Transient behaviour of heat flux was opposite of that of temperature in the plot of heat flux at the four selected locations on the PV as shown in Fig. 6. Flux decreased with an increase in time for all the locations considered for this study. The highest flux was experienced at the side of the PV, while the least effect was recorded at the top of the PV.

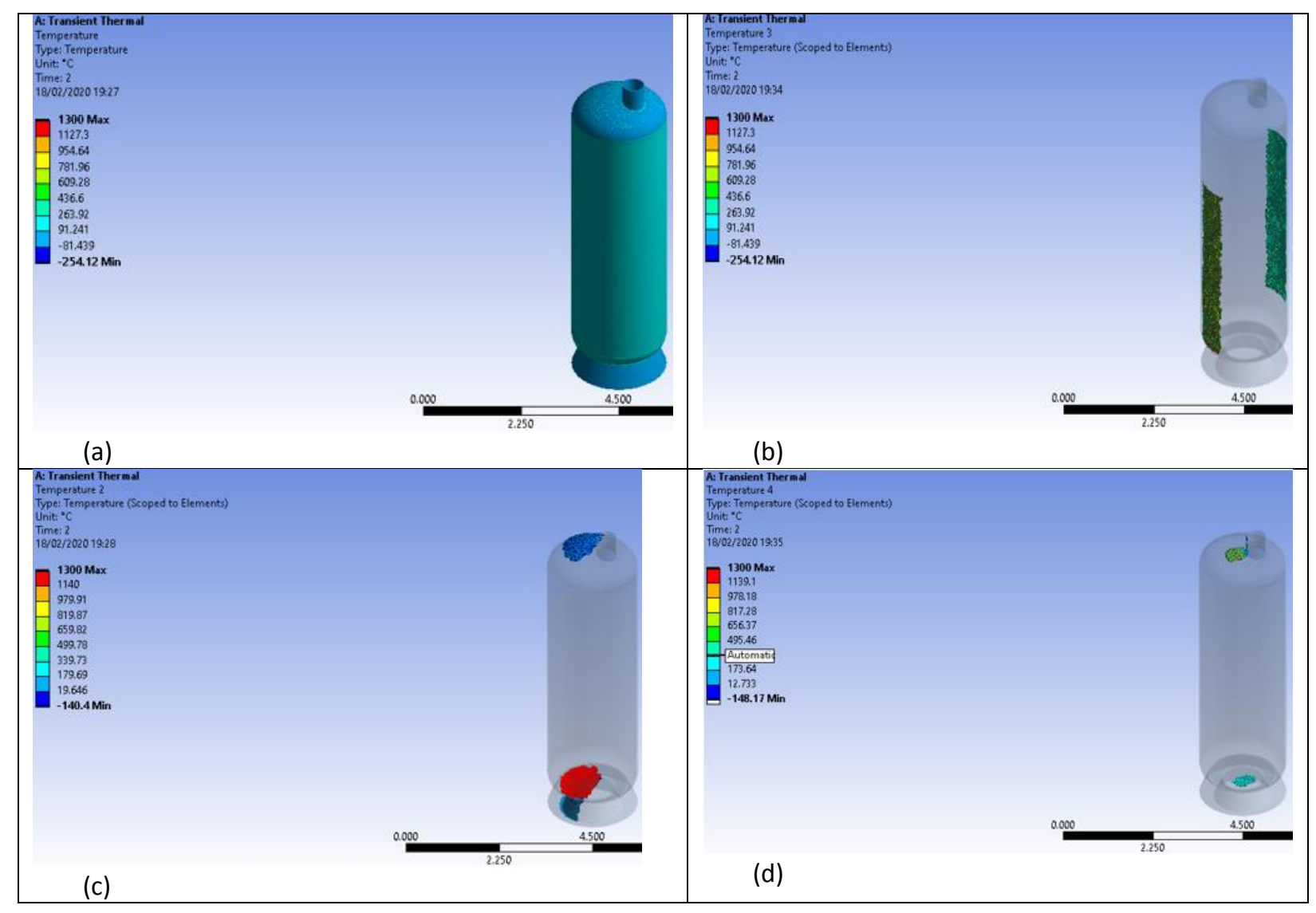

Fig. 3 - Transient behaviour at different locations on PV (a. Total; b. Sides; c. Top; d. Bottom)

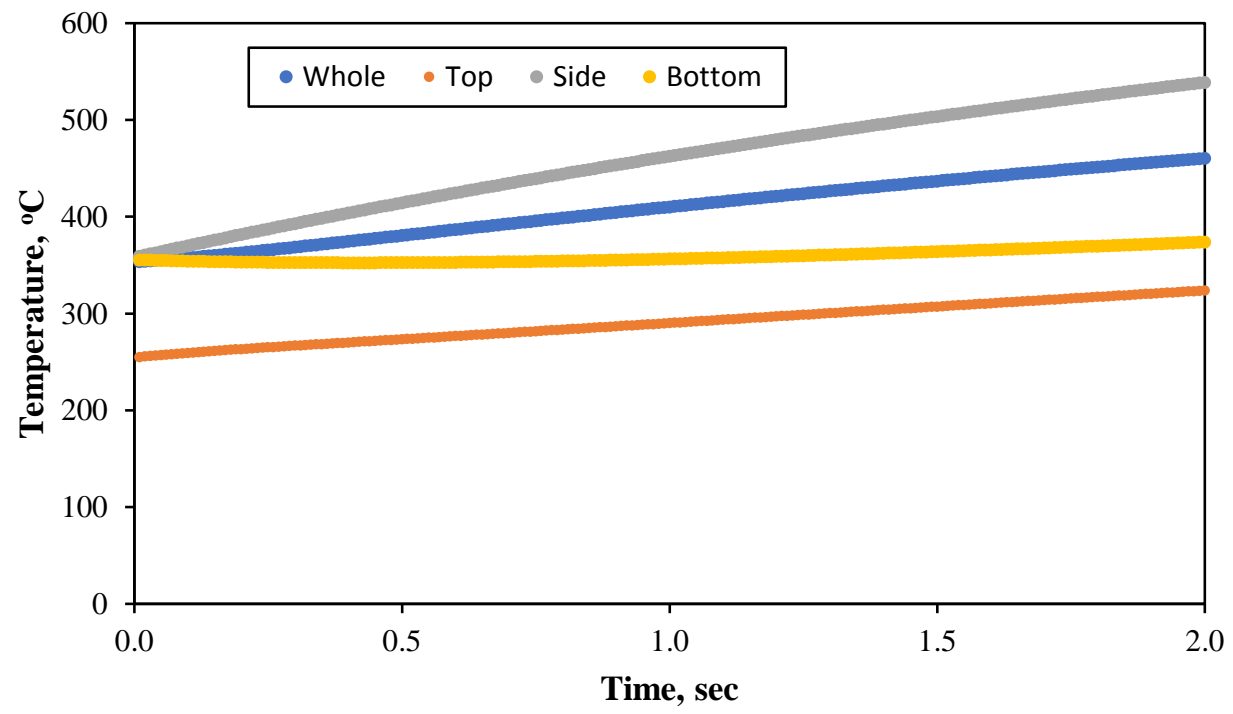

Fig. 4 - Temperature behaviour at different locations on PV 


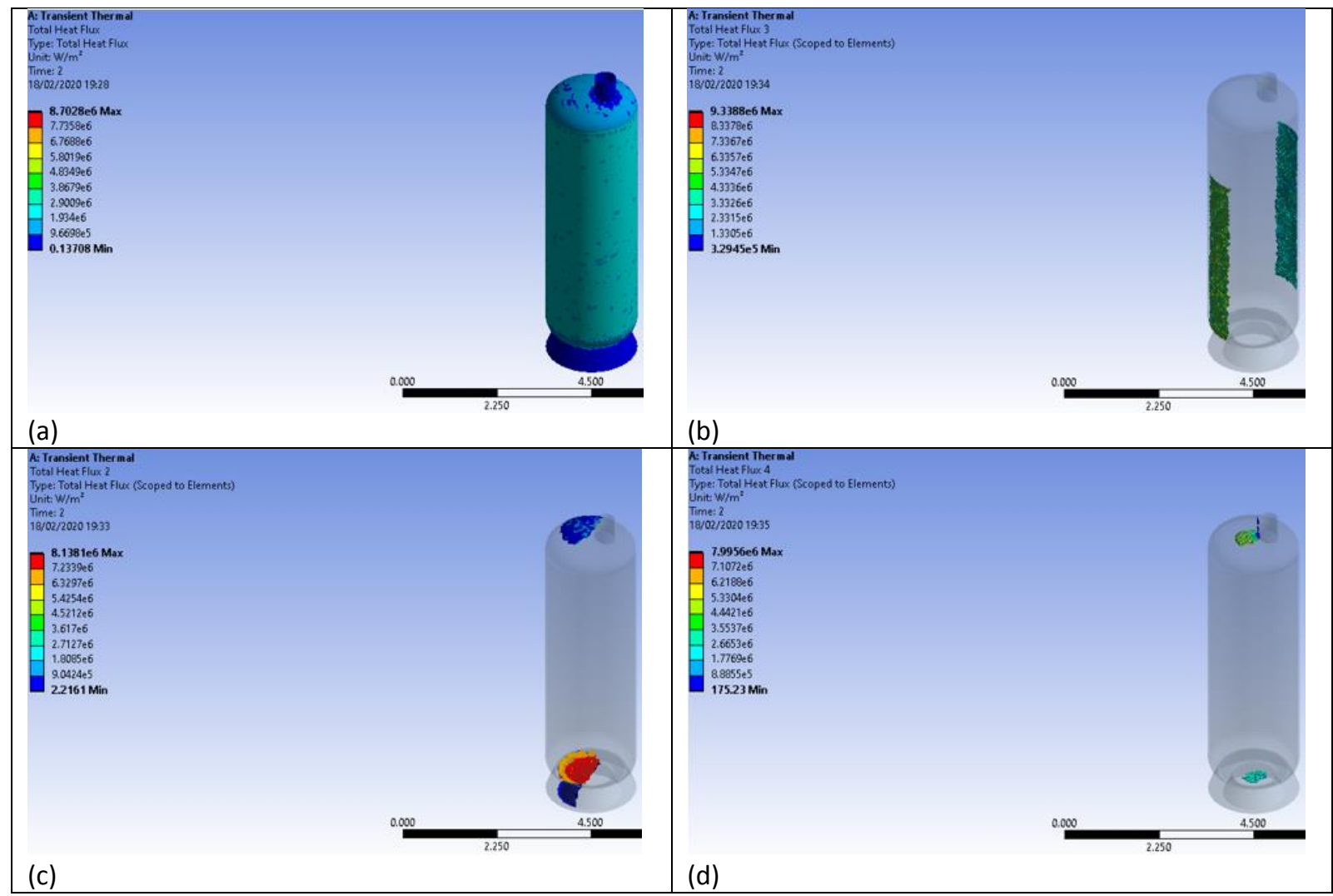

Fig. 5 - Heat flux behaviour at different locations on the PV (a. Total; b. Sides; c. Top; d. Bottom)

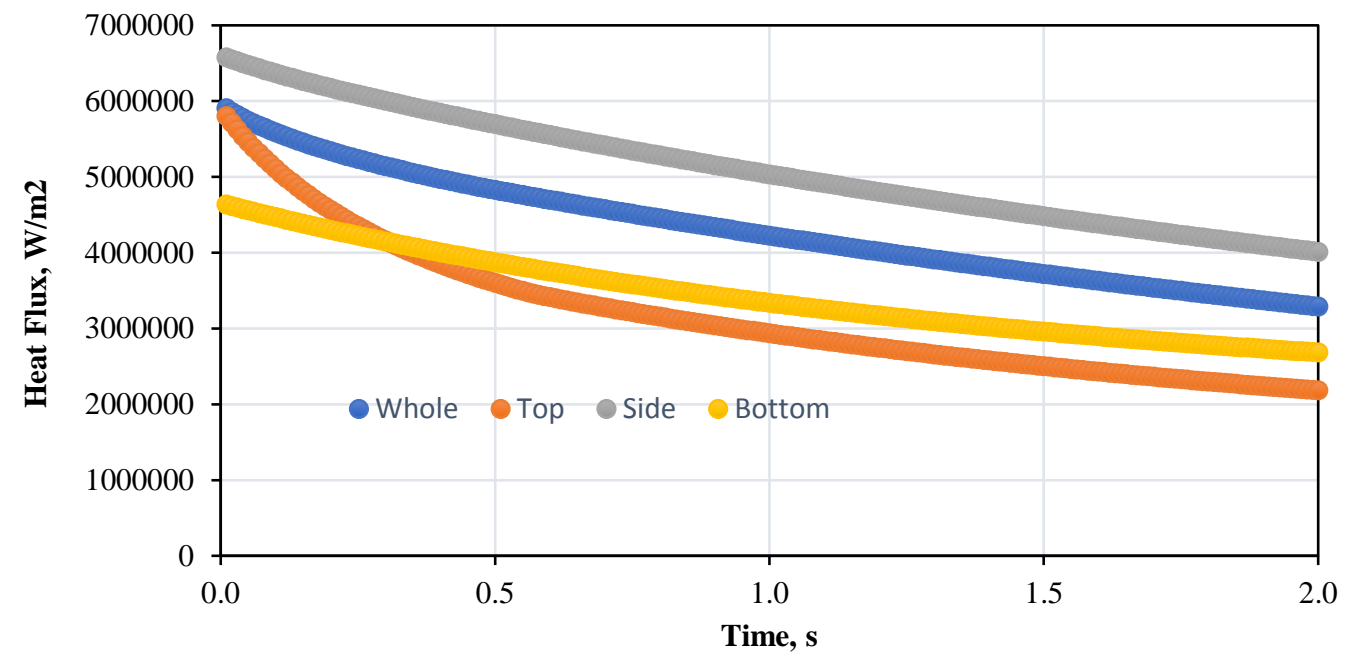

Fig. 6 - Heat flux behaviour at different locations on PV

\subsection{Structural Analysis}

Structural analysis was used to determine the impact of the transient distribution on the structural integrity of the PV under the influence of imported load (from transient analysis). The result of the behaviour of maximum principal stress, structural deformation, maximum elastic strain and the maximum shear elastic strain was presented in Fig. 7. The maximum principal stress varied from - $-4.68 \times 10^{-8}$ to $2.57 \times 10^{9}$. The maximum principal stress computed by ANSYS was close to that computed using the analytical method $\left(2.64 \times 10^{-9} \mathrm{~Pa}\right)$.

The error deviation from the analytical one was $2.65 \%$. Maximum principal stress was observed at some locations at the top and towards the bottom of the PV. The transient analysis results have shown that high transient and heat flux are high at the top and towards the bottom, so, therefore, maximum principal stress was higher in the identified locations from previous studies. 
The deformation experienced on the vertical PV showed that the bottom of the PV felt the structural deformation more when compared with other parts of the PV. The farther from the bottom of the PV, the lesser the deformation experienced. The deformation decreased from $43639 \mathrm{~m}$ at the bottom of the PV to $43559 \mathrm{~m}$ at the top of the PV. The maximum elastic strain and maximum shear elastic strain effect were higher at the PV walls compared to what was recorded at both the bottom and the top of the PV. The maximum elastic strain values varied from 0.00037 to 0.018 , while maximum shear elastic strain values varied from 0.0000064 to 0.027 .

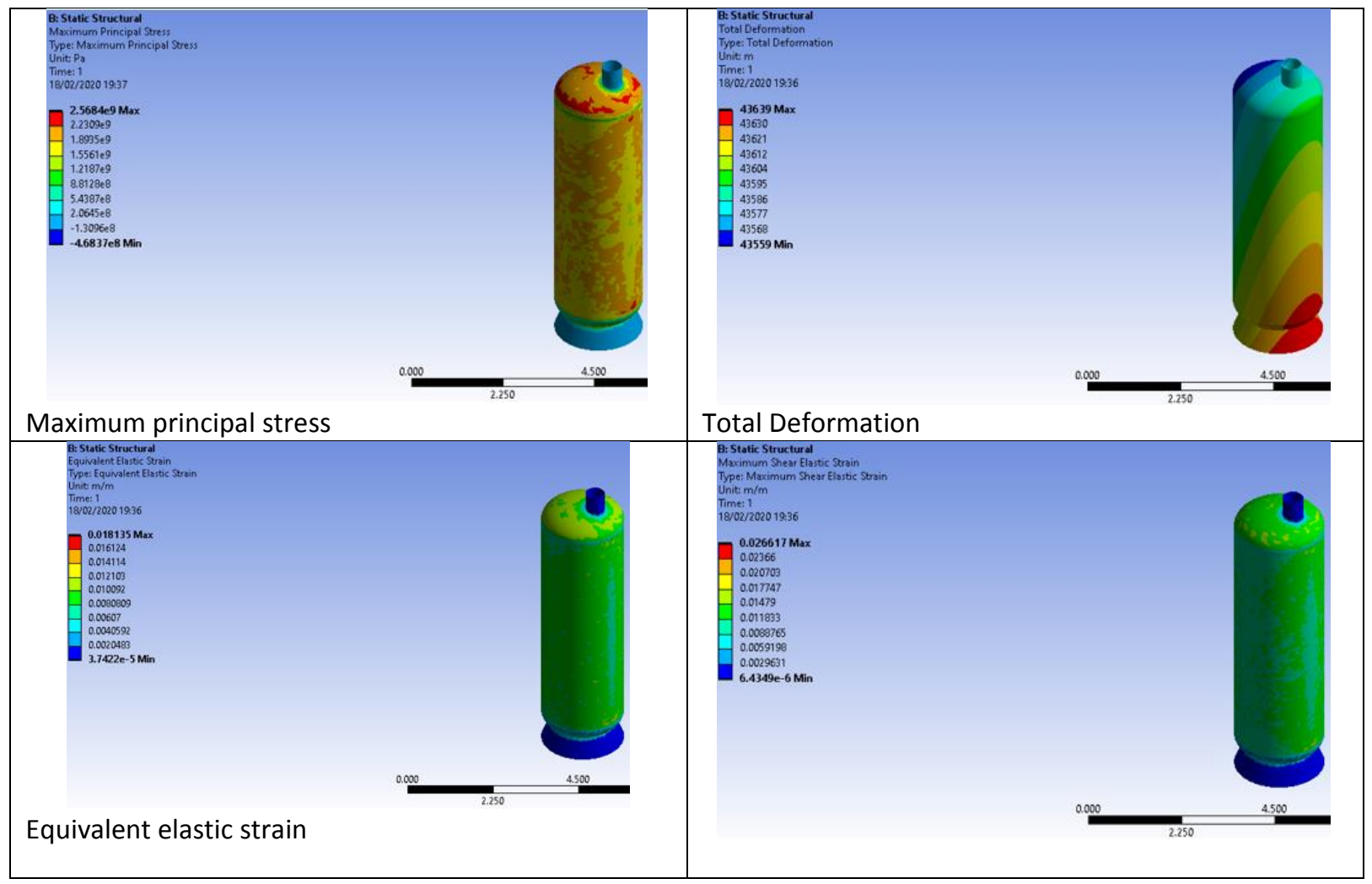

Fig. 7 - Stress analysis of the PV used in this investigation

The plot of equivalent elastic strain and total deformation are plotted against time as shown in Fig. 8 shows two trends. At the first trend, an increase in time lead to a corresponding increase in both values of equivalent elastic strain and total deformation. Equivalent strain increased from 0.002 to 0.012 , after which further increase in time did not appreciably change the value of equivalent elastic strain experienced by the PV. For the case of total deformation, the deformation values increased $3.49 \times 10^{5}$ from zero when the time was increased to $3 \mathrm{sec}$, after which further exposure did not appreciably change the value of deformation.

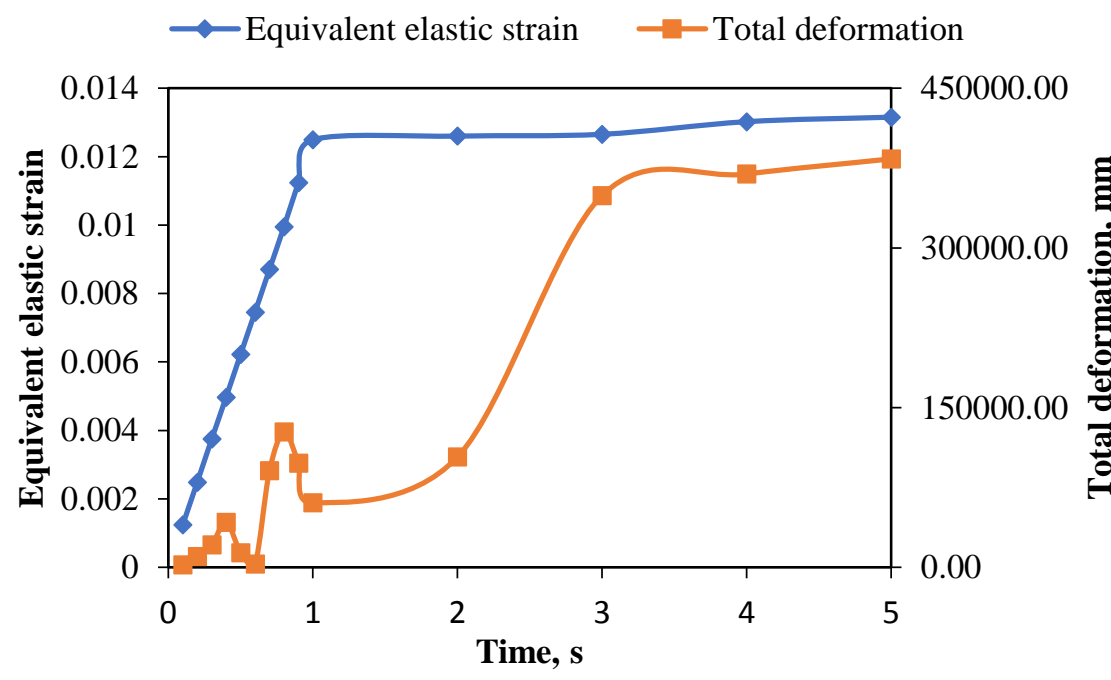

Fig. 8 - Transient of equivalent strain and total deformation on PV 
The plot of maximum shear strain and maximum principal stress presented in Fig. 9 showed an increase in both maximum shear strain and maximum principal stress when the time was increased to 1 second. After 1 second, both the maximum shear strain and maximum principal stress values are with further increase in time, respectively.

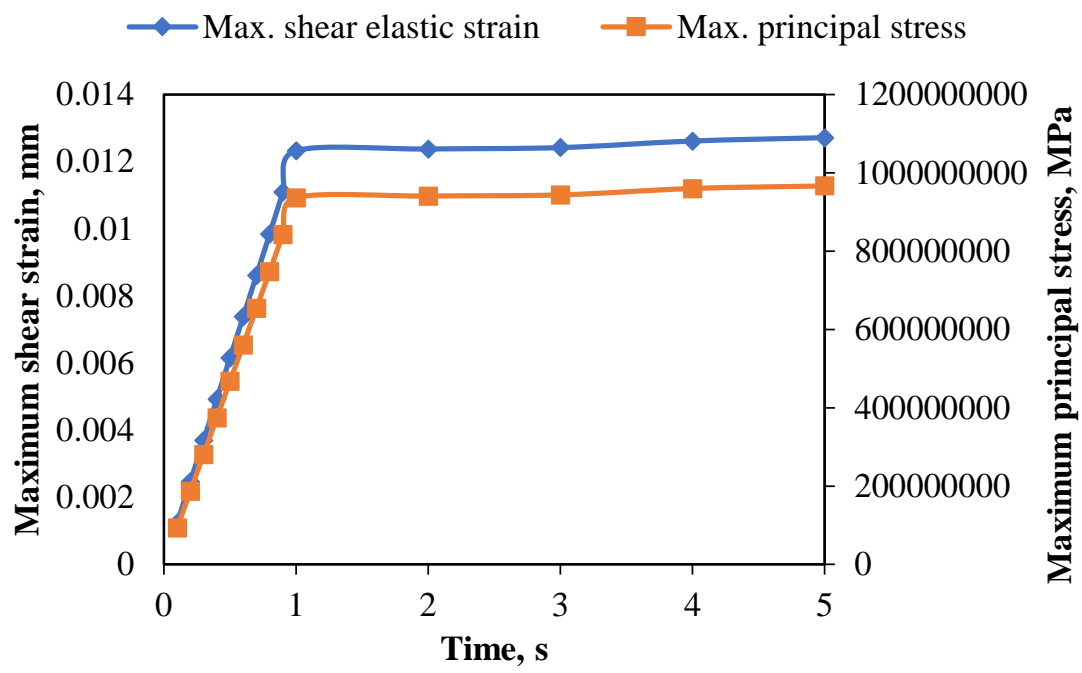

Fig. 9 - Transient of maximum shear elastic strain and maximum principal stress on PV

\section{Conclusion}

From the FEA simulation of the thermal-stress analysis of vertical PV, the following were deduced:

1. Out of the four locations considered within the PV, walls of PV have the greatest effect for both temperature and heat flux when load was imposed on vertical PV.

2. The four parameters considered for structural analysis, total deformation, equivalent strain, maximum shear elastic strain and Maximum principal stress are all time-dependent parameters.

3. The level of prediction and analysis from this simulation was high from the results of simulated maximum principal stress $\left(2.57 \times 10^{9} \mathrm{~Pa}\right)$ which was closer to the analytically computed stress $\left(2.64 \times 10^{9} \mathrm{~Pa}\right)$.

4. The values for GCI, error and MS as element size tend to zero show that the results obtained are independent of the mesh used for the study.

5. It is expected that coating as a means of insulation should be considered when designing PV so as to mitigate heat generation during loading, transient analysis should be investigated for other metals used for PV design and lastly, sensitivity assessment of mesh sizes and other meshing techniques on PV analysis should be explored for PV design.

\section{References}

[1] I. Satyanarayana and K. Praveena, "Design And Analysis of the Pressure Vessel by using FEM," Int. J. Innov. Sci. Eng. Technol., vol. 3, no. 10, pp. 145-150, 2016

[2] S. Prasanth, Durga; Hassan, "Design and analysis of pressure vessel," Int. J. Mech. Prod. Eng. Res. Dev., vol. 9, no. 5 , pp. $125-136,2019$

[3] S. S. . V. P. Viraj H. Barge;Gawade, "Thermal-Structural Analysis and Optimization of Pressure Vessel using Finite Element Analysis," Int. J. Adv. Eng. Res. Stud., vol. 2, no. 4, pp. 104-106, 2013

[4] A. Choudhury, S. C. Mondol, and S. Sarkar, "Finite Element Analysis of Transient Thermo Mechanical Stresses of Multilayered Composite," Int. J. Res. Appl. Sci. Eng. Technol., vol. 3, no. 8, pp. 274-284, 2015

[5] Y. Katsuyama, Jinya; Uno Shummpei; Watanabe, Tadashi; and Li, "Influence Evaluation of Loading Conditions during Pressurized Thermal Shock Transients based on Thermal-Hydraulics and Structural Analyses," Front. Mech. Engg., pp. 1-8, 2018

[6] G. Gálik, V. Kutiš, J. Paulech, and V. Goga, "Termo-Hydraulics and Termo-Mechanical Lading of VVER-440 Reactor Pressure Vessel," in Applied Mechanics, 2018, pp. 31-36

[7] G. Gálik, V. Kutiš, J. Paulech, and J. Murín, "CFD modeling of transient fluid-flow during LOCA event in a VVER440 / 213 reactor CFD Modeling of Transient Fluid-flow During LOCA Event in a VVER440 / 213 Reactor," in Applied Phhysics of Condensed Matter (APCOM 2019), 2019, vol. 020013, no. July, pp. 1-5

[8] M. Niffenegger, G. Qian, M. Sharabi, and N. Lafferty, "Analysis of a Reactor Pressure Vessel Subjected to Pressurised Thermal Shocks,” Int. J. Comp. Meth. Exp. Meas., vol. 4, no. 3, pp. 288-300, 2016, doi: 10.2495/CMEM-V4-N3-288-300

[9] C. B. Maklago, Erick Wasonga; Namgungg, Ihn; Hwang, "Static Structural and Thermal Analysis of APR1400 
Reactor Pressure Vessel," in Transaction of the Korean Nuclear Society Spring Meeting, May 22-24, 2019, 2019, pp. 1-3

[10] D. Bhoknal, Snehal and Deshmukh, "Transient Dynamic Stress Analysis of Mixing Chamber Applied For Chemical Industry," J. Enggineering Res. Appl., vol. 8, no. 7, pp. 6-12, 2018, doi: 10.9790/9622-0807050612

[11] M. Ambarita, H; Siahaan, A. S; Kawai, H., and Diamaruya, "Transient thermal stresses analysis and thermal fatigue damage evaluation for skirt attachment of coke drum Transient thermal stresses analysis and thermal fatigue damage evaluation for skirt attachment of coke drum," Mater. Sci. Eng., vol. 308, pp. 1-8, 2018, doi: 10.1088/1757-899X/308/1/012029

[12] ASME BPVC, “An International Code ASME Boiler \& Pressure Vessel Code, Section II MATERIALS Part A Ferrous Material Specifications (Beginning to SA-450)," in ASME, 2019, pp. 1-128

[13] Faro, Abdulfatai, A., Salam, Kazeem, K., Alagbe, E., "Design and Analysis of a Vertical Pressure Vessel with Effect of Rotational Velocity on the Stresses and Deformation by using ANSYS," Int. J. Anal. Exp. Finite Elem. Anal., vol. 6, no. 3, pp. 110-120, 2019, doi: 10.26706/IJAEFEA.3.6.20190702

[14] OCW-MIT, "Introduction to Engineering Heat Transfer." pp. 1-74, 2002

[15] ASME V\&V 10, An Illustration of the Concept of Verification and Validation in Computational Solid Mechanics. 2012

[16] P. J. Roache, Fundamentals of Verification. Albuquerque: Hermosa, 2009

[17] S. S. Kulkarni, C. Chapman, and H. Shah, "Computational Fluid Dynamics ( CFD ) Mesh Independency Study of A Straight Blade Horizontal Axis Tidal Turbine," Preprint, pp. 1-11, 2016, doi: 10.20944/preprints201608.0008.v1 